\title{
The Effectiveness of Changes in Street Layout and Design for Reducing Barriers to Walking
}

\author{
Paulo Rui Anciaes \\ Centre for Transport Studies, University College London, Chadwick Building, Gower Street, \\ London WC1E 6BT, United Kingdom.

\section{Peter Jones} \\ Centre for Transport Studies, University College London, Chadwick Building, Gower Street, \\ London WC1E 6BT, United Kingdom.
}

\begin{abstract}
This study analyses the effectiveness of two types of interventions to reduce built environment barriers to walking: changing the layout of the local street network (by increasing the density and connectivity of the links available to pedestrians) and redesigning a busy road (by adding crossing facilities, reducing the speed limit, or reallocating road space to pedestrians). The analysis focuses on a residential neighborhood in London which is being extensively redeveloped. The anticipated effects of the interventions are assessed in terms of the distance, delay, risk, and environmental quality of walking trips from residences to public transport nodes. The study also addresses methodological issues, by modelling the off-street space available to pedestrians and considering alternative hypotheses for pedestrian route choice. The results show that in this neighborhood, changes to the street layout always reduce delay and improve the pedestrian environment, although they may increase trip distances and collision risk. Adding crossing facilities reduces risk but does not decrease delay, while reducing the number of vehicle lanes reduces distance and delay but may increase risk. All types of intervention improve the pedestrian environment, even in the cases of routes chosen to minimize delay or exposure to traffic.
\end{abstract}

\section{INTRODUCTION}

The promotion of walking has become a policy priority in many countries, given the growing evidence of the role of physical exercise in improving individual health (1) and wellbeing (2, 3). However, the propensity to walk depends on neighborhood attributes such as the connectivity of the local street network, the presence of busy roads, and the quality of the pedestrian environment. These factors have an impact on levels of accessibility to local destinations, collision risk, and the experience of walking.

The paper analyses the effects of interventions to reduce barriers to walking in a neighborhood in London facing radical changes due to a major redevelopment program. The study simulates the effects of planned changes to the street layout and compares eight different options for redesigning the main road running through the neighborhood. These options comprise the construction of new pedestrian crossing facilities, the reduction of the speed limit, and the reallocation of road lanes from motorized traffic to pedestrians.

The analysis also addresses methodological issues regarding pedestrian route choice. The choice set contains all space that can be used by pedestrians, including informal links and crossings. Different objectives are defined for route choice decisions, based not only on trip distance and duration, but also on exposure to traffic and the quality of the pedestrian 
environment. Local conditions were assessed using a video survey and a street audit. GIS-based network analysis was then used to estimate walking routes to public transport nodes, and statistics on trip distance, delay, risk, and environmental quality were calculated for the alternative route choice objectives applied to all intervention scenarios.

\section{BACKGROUND}

\section{Barriers to walking}

The local built environment tends to influence people's propensity to walk and to engage in physical activity (4). Pedestrians often face physical and psychological barriers, which may be absolute (features of the built environment that prevent pedestrian movement) or relative (features that are perceived as negative and whose presence dissuades people from walking). However, the influence of the built environment on walking is mediated by individual and social factors. Interventions to improve local walkability tend to have a higher impact on some groups, such as the less healthy, and the unemployed and retired (5).

The characteristics of the local street network play a crucial role. In particular, the density, connectivity, and configuration of the network are often associated with observed levels of walking $(6,7,8)$. This may be because in sparse and poorly connected street networks, walking trips tend to be lengthier and less direct, leading individuals to choose other means of transport or to make fewer walking trips.

Pedestrian movement is also restricted by the need to cross major transport infrastructure, such as railways and major roads. There is evidence that walking and street life are negatively affected by large traffic volumes (9) or higher speeds (10), which manifests in detours or delays to walking trips, the effort or inconvenience required to use crossing facilities, exposure to air pollution and noise, and psychological effects.

Pedestrians also experience barriers when walking along roads and streets. In fact, the propensity to walk tends to be related to functional aspects of walking routes, such as the quality and condition of sidewalks $(11,12)$. Fear of crime can also be a deterrent to walking (13), especially in streets with poor lighting or low footfall. Elderly or disabled pedestrians can also find it challenging to walk along streets with slopes, steps, undulations, or obstructions (14).

\section{Pedestrian behavior}

Despite the growing evidence of the links between the built environment, walking, health, and wellbeing, there is still relatively little knowledge about the effects of barriers on the way that pedestrians use the street network and their strategies to overcome these barriers.

The results of empirical studies on the effect of barriers on pedestrians are sensitive to hypotheses regarding route choice. The modelling of the choice set is often incomplete, leaving out many informal links that are normally used as cut-throughs, such as parks, shopping centers, train stations, and car parks. The exclusion of these links may lead to an underestimation of levels of accessibility and street connectivity $(15,16)$. On the other hand, it should not be assumed that all the links on the street network are available to pedestrians, as they may not have sidewalks or other essential pedestrian infrastructure.

The hypothesis that pedestrians take the shortest or fastest route should also be questioned, as route choice is influenced by the quality of the street environment (17). There is evidence that pedestrians trade-off walking distance or time with the effort and disutility of overcoming obstacles such as steps or road traffic $(18,19)$. Differences in the use of street segments in a given area are also explained by aspects such as sidewalk width and the presence of crossing facilities (20).

Recent studies have started to include information about the pedestrian environment in the estimation of walking routes. For example, 3D data has been used to generate routes that 
consider aspects such as scenery, slopes, and areas susceptible to flooding (21). Stated and revealed preference surveys have also been used to determine the extent to which the pedestrian environment explains the deviation of actual routes from the shortest routes $(22,23)$. When applied in conjunction with similar assessments for other modes of transport, this information can be useful to estimate the impacts of interventions such as road space reallocation (24).

The present study addresses these issues, by assessing the impacts of interventions taking into consideration the whole space that is available for use by pedestrians, and by testing the sensitivity of results to alternative hypotheses regarding route choice.

\section{CASE STUDY}

Woodberry Down is a residential neighborhood in London, surrounded by physical barriers: a canal (with no bridges to the other side), two water reservoirs, and a busy road (Green Lanes) (Figure 1). The area is also crossed by Seven Sisters Road, a road with six traffic lanes and high traffic levels and speeds. There is only one formal pedestrian crossing along the $800 \mathrm{~m}$ section of the road that runs through the neighborhood. The subway station and the bus stops located on this road are the main destinations for walking trips, due to the limited number of shops and other facilities in this area. As such, crossing problems have implications for accessibility and levels of physical exercise of the local population.



(a)

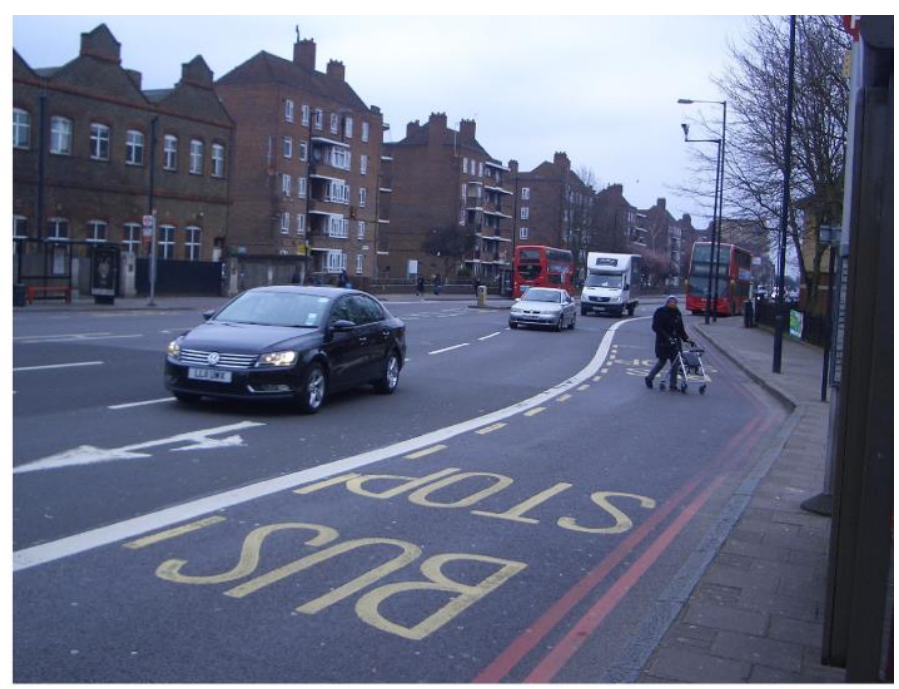

(b)

Map (a): (C) Copyright and Database Right 2016. Ordnance Survey (Digimap License)

\section{FIGURE 1 Woodberry Down (a) and Seven Sisters Road (b).}

This paper is a part of a larger research project developing tools to identify and overcome barriers to walking. A household survey and mapping workshops revealed that Seven Sisters Road is perceived as an unpleasant place due to the presence of high volumes of motorized traffic. Local residents often avoid crossing or walking along this road by choosing alternative routes. A stated preference survey has shown that residents are willing to walk for longer times in order to avoid crossing busy roads in a place without crossing facilities. A video survey has also shown that informal crossings occur when pedestrians want to access bus stops on the other side of the road.

Woodberry Down is a good case study to analyze the effects of changes in the built environment because the area is currently going through an extensive program of 
redevelopment, which involves the replacement of the majority of the housing stock and the reformulation of the local street network. There are also plans to improve the street environment and increase the ease of crossing Seven Sisters Road. It is hoped that the present study demonstrates the benefits of the new street layout and informs decision-makers about the desirability of implementing each of the different options for Seven Sisters Road.

\section{MODELLING INTERVENTIONS TO REDUCE BARRIERS}

\section{Changes to street layout}

The first step in the analysis was to model the pedestrian network, including all the formal and informal links and crossings that may be used by pedestrians, in the pre and post-redevelopment scenario. The post-redevelopment network is based on the most up-to-date masterplan for the area.

The sidewalks on both sides of the road were identified as separate links in the case of the two roads mentioned above (Green Lanes and Seven Sisters Road) and in two other main roads inside the neighborhood. The links were split at junctions, or wherever the pedestrian environment changes significantly. Only one link was assigned to minor roads and streets, representing the conditions of the sidewalks on both sides of the road. The set of links includes spaces that are not formal streets but are available for the movement of pedestrians, such as passageways linking buildings, courtyards, canal pathways, and parks. The median strip of Seven Sisters Road was also modelled, as video footage revealed that many pedestrians use it not only to break their crossing into two sections but also to walk along its length.

Pedestrian crossings were modelled for the four main roads. The set of crossings includes all the formal crossing facilities and the locations where pedestrians may cross informally, such as at bus stops, junctions, and other locations identified in the video survey.

The impact of the planned changes in the pedestrian network is evident from Figure 2. The pre-redevelopment network is sparse and has very poor connectivity. There are few links connecting the northwest part with the rest of the neighborhood and connecting the different streets within the south-western and south-eastern parts. In the post-redevelopment scenario, the street network (links available to vehicles and pedestrians) remain sparse but a high degree of connectivity is achieved through a dense network of links that are exclusive to pedestrians (through new squares and parks). 
Pre-redevelopment

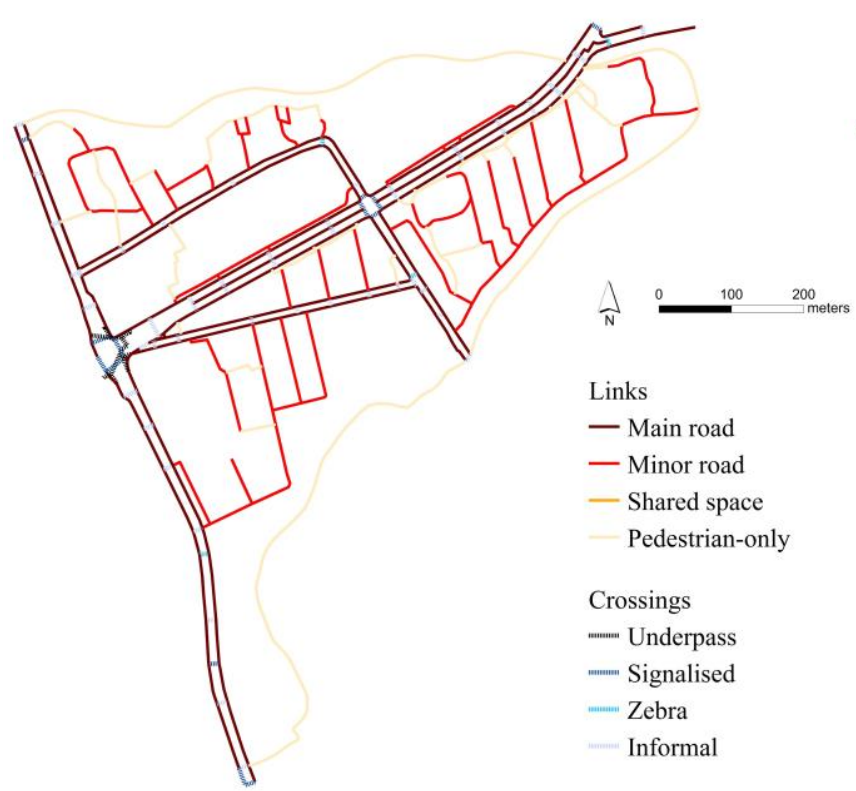

Post-redevelopment



FIGURE 2 Pre- and post-development pedestrian network.

\section{Changes to Seven Sisters Road}

Table 1 lists eight options for redesigning Seven Sisters Road to reduce the barrier effect. Some of these proposals are included in the planning application for the site $(25,26)$ or are being considered by the local authorities. Options A to $\mathrm{C}$ maintain the existing number of lanes but improve the ease of crossing the road, by adding crossing facilities in the western and eastern parts of the neighborhood or imposing a speed limit of $20 \mathrm{mph}$ (the current limit is $30 \mathrm{mph}$ ). Options D and E reallocate two existing vehicle lanes to pedestrians. Option F reallocates four lanes to pedestrians. Option $\mathrm{G}$ is a wide one-lane 'shared space' and Option $\mathrm{H}$ removes above ground motorized traffic completely by building a road tunnel.

\section{TABLE 1 Options For Improving Seven Sisters Road}

\begin{tabular}{llll} 
& Number of lanes & New crossing facilities & Use of reallocated space \\
\hline A & 6 & 2 signalised crossings & - \\
B & 6 & 2 underpasses & - \\
C & $6(20 \mathrm{mph}$ speed limit $)$ & - & - \\
\hline D & 4 & - & Wider sidewalk \\
E & 4 & - & Wider median strip \\
\hline F & 2 & - & Wider sidewalk \\
\hline G & 1 (Shared space) & - & - \\
\hline H & 0 (Tunnel) & - & - \\
\hline
\end{tabular}

Note: “-": not applicable

\section{CROSSING PROBLEMS}

A series of attributes was measured to determine the extent to which the four main roads are currently a barrier to the movement of pedestrians. Values for traffic volumes and speeds were identified through the video survey. Pedestrian delay is defined as the sum of the observed waiting time at the roadside and in the median strip. These times were calculated by taking the 
average of the waiting times of the pedestrians crossing the road in the first 15 minutes of every hour, from 8 am to $10 \mathrm{pm}$.

It is assumed that traffic speeds will fall to $20 \mathrm{mph}$ in Option A in the crossings next to the new traffic lights and in all crossings in Seven Sisters Road in Options D and E, and to $10 \mathrm{mph}$ in Options $\mathrm{F}$ and $\mathrm{G}$ in all crossings. This is due to anticipated congestion caused by the new crossings or by the reduction of vehicle lanes in the absence of alternatives routes for motorized traffic. Crossing delays will also fall due to the reduced speed and, in Option E, also due to improvements to the median strip.

\section{PEDESTRIAN ENVIRONMENT}

A street audit was conducted to assess the pedestrian environment on all links and crossings of the network, using the Pedestrian Environment Review System (PERS), a framework developed by the Transport Research Laboratory (TRL) (27). A number of strategies were implemented to reduce subjectivity. Quality standards were defined in advance, by ranking, for each of the attributes assessed, a set of 45 streets around Greater London. Three different auditors assessed a sample of links in the study area. The main stage of the street audit then involved several field trips at different times of day on weekdays and at weekends, and under dry and rainy weather conditions.

In assessing the pre-redevelopment scenario, the links that have already been removed from the network were rated by looking at street maps and considering similar existing links elsewhere in the area. In the post-redevelopment scenario, the existing links were rated from field visits. The rating of the links that do not exist yet was based on similar existing links and maps, plans, and simulated images included in planning documents. The assessment of this material considered aspects such as junctions with side roads, possible conflict of movements with cars, and provision for street parking.

Links were assessed based on 14 attributes: effective width, dropped curbs, gradient, obstructions, permeability, legibility, lighting, tactile information, color contrast, personal security, surface quality, user conflict, environment, and maintenance. Crossings were assessed based on 12 attributes: provision, deviation from desire lines, performance, capacity, delay, legibility, legibility for sensory impaired people, dropped curbs, gradient, obstructions, surface quality, and maintenance. Each attribute was scored on a seven-point scale. The overall score was obtained by using a set of weights, recommended by TRL (28), and converting the result to a percentage scale. The higher the score, the better the outcome.

Figure 3 shows the striking difference between the PERS scores in the pre- and postredevelopment scenarios. The poor scores of Seven Sisters Road in the pre-redevelopment case are explained by the presence of barriers that are not related with motorized traffic, such as sidewalk obstructions, conflict with other users, and lack of dropped curbs at the many junctions with side roads and entrances to garages. However, some links that could provide an alternative to walking along Seven Sisters Road also fare poorly because of problems such as sidewalk parking and poor lighting. The scores in the post-redevelopment scenario are above $50 \%$ in most cases except in Green Lanes and in the Eastern part of the neighborhood (which is excluded from the redevelopment program). 

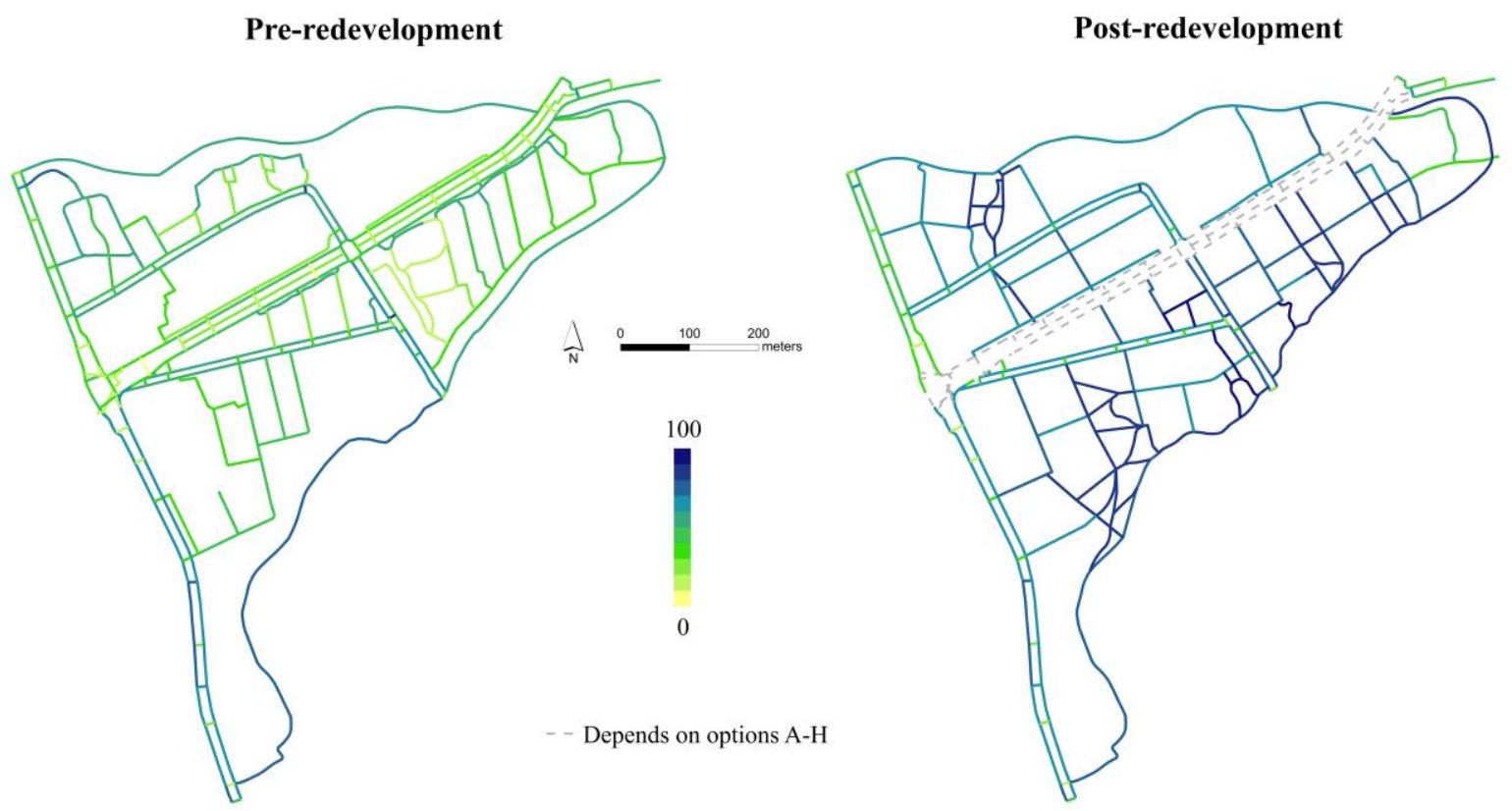

FIGURE 3 Pre- and post-development PERS scores.

The PERS scores of the crossings in Seven Sisters Road vary for the options A-H. For example, scores rise in options A and B as informal crossings become formal crossings, and in option A, also because vehicles have to stop at two additional traffic lights, reducing average speed. Scores rise in Option $\mathrm{C}$ as the crossing performance and delay attributes of the PERS assessment improve, and in options $\mathrm{D}$ and $\mathrm{H}$, also because of better crossing provision and legibility. The improvement is highest in options F-H, as crossing becomes considerably easier.

The PERS scores of the links along Seven Sisters Road rise in all options due to improvements in permeability (the size of which depends on the option), and in the case of options D and F-H, also due to the wider pedestrian space and the lower impact of sidewalk obstructions. User conflict is reduced in options $\mathrm{D}, \mathrm{F}$, and $\mathrm{H}$ (wider sidewalks, and road tunnel) but not in Option $\mathrm{G}$ (shared space). Option $\mathrm{H}$ is also linked with improvements in legibility and personal security. Anticipated improvements in dropped curbs, maintenance, surface quality, tactile information, and color contrast apply to all the options.

\section{IMPACTS OF INTERVENTIONS}

\section{Methods}

Network analysis was used to estimate the optimal routes between all residential buildings and public transport nodes, given different route choice objectives. The set of nodes includes an underground station and the nearest bus stops for all bus lines serving the neighborhood. In practice, five routes are estimated for each building: one to the station and the other four to stops on both sides of Seven Sisters Road and Green Lanes.

The spatial distribution of buildings is different in the pre- and post-redevelopment scenarios. In order to isolate the impacts of changes in the street layout and road design from the impact of changes in building location, the analysis for the pre-redevelopment scenario was carried out twice, using the old and new building locations. The estimation of the optimal routes used the Arc GIS 10.2 Network Analyst tool. Table 2 describes the four alternative objectives for pedestrian route choice. 
TABLE 2 Alternative Route Objectives

Route Choice Impedance value

\begin{tabular}{lcc}
\hline & Links & Crossings \\
\hline Shortest & distance & distance \\
Fastest & time & time + delay \\
Minimize exposure to traffic & time & time + willingness to walk to avoid risk \\
Maximize environmental quality & time * (1-PERS) & time * (1-PERS) \\
\hline
\end{tabular}

The shortest route is based only on network distance. It should be noticed that the shortest routes are the same for all options A-H for redesigning Seven Sisters Road, as these interventions do not alter the length of any link or crossing.

The fastest route uses average pedestrian speed as measured in the video survey or by taking a value of $5 \mathrm{~km} /$ hour in other cases. Road crossings are more onerous than links due to added waiting time to start crossing the road. In major roads, this is compounded by the reduction of average speed due to the need to stop in the median strip, but mitigated in some cases (especially in informal crossings) by the fact that pedestrians run across the road.

The route objective that minimizes exposure to traffic adds to informal crossing times the extra time people are willing to walk to avoid crossing a road in a location without designated facilities. Waiting time is not considered here, as it is assumed that this time is already taken into account in people's trade-off values. The times were obtained by a stated preference survey in which 100 residents choose between crossing the road in a place without designated facilities, walk to use the nearest facility, or avoid crossing altogether. The extra times were estimated for different combinations of the number of traffic lanes, traffic speeds, and presence of a median strip. In roads with six lanes, the value is 0.4 minutes (when $20>$ speed $>30 \mathrm{mph}$, with median strip), 7.6 minutes (20>speed $>30 \mathrm{mph}$, no median strip), 4.9 minutes (speed $=30 \mathrm{mph}$, with median strip) or 12.1 minutes (speed $=30 \mathrm{mph}$, no median strip). In roads with four lanes and speed $=30 \mathrm{mph}$ the value is 5.7 minutes.

The route that maximizes environmental quality is based on the hypothesis that the higher the quality of the pedestrian environment (as measured by the PERS score), the less pedestrians will perceive walking time as a cost. Pedestrians will then minimize the time spent walking along links with the worst possible conditions $(\mathrm{PERS}=0)$ and enjoy walking on links with the best possible conditions (PERS $=1$ ) regardless of the time spent. Under this hypothesis, the cost of traversing a link is equal to walking time discounted with the indicator of the quality of the environment. Waiting time is not added to walking time in this formulation, as delay is already included as one of the attributes considered in the PERS assessment of the crossing.

The set of optimal routes obtained from the network analysis was then used to calculate statistics for the distance, delay, risk, and environmental quality of all pedestrian trips. This enables a comparison between the pre-redevelopment and post-redevelopment street layouts (based on both the past and future building distributions) and between the eight options for Seven Sisters Road (all of them based on the future street layout and building distribution).

The values are the averages for the trips between all residential buildings and public transport nodes. In these averages, residential buildings are weighted by their proportion of the neighborhood population. This proportion was estimated taking into account the building area and the number of floors (identified on field visits or in planning application documents)

\section{Results: Walking distances}

Table 3 shows the average distance of the simulated trips under each scenario (i.e. different street and building layouts, and improvements to Seven Sisters Road) and route choice objective. 
TABLE 3 Average Walking Distance For Each Scenario (meters)

\begin{tabular}{lcccc}
\hline Scenario & \multicolumn{5}{c}{ Routes } \\
\hline & Shortest & Fastest & Min traffic & Max quality \\
\hline No changes to Seven Sisters Road & & & & \\
\hline Past street layout & 347 & 350 & 362 & 390 \\
Past street layout (new buildings) & 347 & 351 & 362 & 387 \\
Future street layout & 326 & 327 & 341 & 393 \\
\hline
\end{tabular}

Changes to Seven Sisters Road (new street layout)

\begin{tabular}{lllll} 
layout) & & & & \\
\hline A: signalised crossings & 326 & 327 & 336 & 389 \\
B: underpasses & 326 & 327 & 336 & 385 \\
C: reduce speed limit & 326 & 327 & 340 & 385 \\
\hline D: wider sidewalk & 326 & 328 & 329 & 373 \\
E: wider median strip & 326 & 328 & 329 & 386 \\
\hline F: much wider sidewalk & 326 & 328 & 328 & 365 \\
\hline G: shared space & 326 & 328 & 328 & 374 \\
\hline H: road tunnel & 326 & 328 & 328 & 366 \\
\hline
\end{tabular}

The new street layout decreases the average length of pedestrian trips for the 'shortest', 'fastest', and 'minimize traffic' objectives, but not for the 'maximize environmental quality' objective. The shortest and fastest routes are almost identical under all options for redesigning Seven Sisters Road. The length of the routes that minimize exposure to traffic generally decreases with the number of lanes on Seven Sisters Road. Reducing the speed limit (Option C) has a very small impact on trip length. The average lengths of the trips maximizing environmental quality are shortest for the options with two lanes or less $(\mathrm{F}-\mathrm{H})$.

\section{Results: Delay}

Table 4 shows the average delays experienced under each route choice objective. As previously noted, delay is measured as the sum of waiting times before crossing the road and any time stopped in the median strip, if the road has one.

Delays are slightly reduced for the future street layout, but the addition of crossing facilities (options A and B) does not add to this reduction. The options with fewer vehicle lanes (F-H) reduce delays substantially for all route choice alternatives except the shortest route. The reduction of the speed limit (Option $\mathrm{C}$ ) and the options with four lanes (D and $\mathrm{E}$ ) also reduce delays but to a lesser extent than options F-H. 


\section{TABLE 4 Average Delay For Each Scenario (seconds)}

Scenario

Routes

\begin{tabular}{lcccc}
\hline & Shortest & Fastest & Min traffic & Max quality \\
\hline No changes to Seven Sisters Road & & & & \\
\hline Past street layout & 8 & 6 & 11 & 10 \\
Past street layout (new buildings) & 8 & 6 & 11 & 10 \\
Future street layout & 7 & 5 & 9 & 7 \\
\hline
\end{tabular}

Changes to Seven Sisters Road (new street layout)

\begin{tabular}{lllll}
\hline A: signalised crossings & 7 & 5 & 9 & 7 \\
B: underpasses & 7 & 5 & 9 & 7 \\
C: reduce speed limit & 7 & 4 & 9 & 6 \\
\hline D: wider sidewalk & 7 & 4 & 7 & 6 \\
E: wider median strip & 7 & 3 & 7 & 6 \\
\hline F: much wider sidewalk & 7 & 3 & 5 & 6 \\
\hline G: shared space & 7 & 2 & 5 & 5 \\
\hline H: road tunnel & 7 & 2 & 5 & 3 \\
\hline
\end{tabular}

\section{Results: Risk}

The risk of collision for a pedestrian crossing a road was assessed using a formula proposed by Routledge et al. (29), where risk depends on the average length of a vehicle $(l)$, taken as 4 meters, and the average speed of the traffic flow $(s)$, crossing time $(t)$ and traffic gap $(g)$. The inputs applied for each crossing location were obtained by analyzing the video footage.

$$
\text { risk }=\frac{l+s * t}{g}
$$

A risk indicator was calculated as the average of the risk values for all the road crossings encountered in each pedestrian route. The results are shown in Table 5. 
TABLE 5 Average Risk For Each Scenario (\%)

\begin{tabular}{lcccc}
\hline Scenario & \multicolumn{5}{c}{ Routes } \\
\hline & Shortest & Fastest & Min traffic & Max quality \\
\hline No changes to Seven Sisters Road & & & & \\
\hline Past street layout & 6.9 & 7.3 & 0.1 & 5.7 \\
Past street layout (new buildings) & 6.0 & 6.1 & 0.2 & 4.8 \\
Future street layout & 5.9 & 5.9 & 0.2 & 6.4 \\
\hline
\end{tabular}

Changes to Seven Sisters Road (new street layout)

\begin{tabular}{lllll}
\hline A: signalised crossings & 5.9 & 5.7 & 0.2 & 4.4 \\
B: underpasses & 5.9 & 5.6 & 0.2 & 5.2 \\
C: reduce speed limit & 5.9 & 5.9 & 0.3 & 6.0 \\
\hline D: wider sidewalk & 5.9 & 3.2 & 1.6 & 3.4 \\
E: wider median strip & 5.9 & 3.2 & 1.6 & 3.2 \\
\hline F: much wider sidewalk & 5.9 & 1.4 & 0.9 & 1.4 \\
\hline G: shared space & 5.9 & 1.4 & 0.9 & 1.6 \\
\hline H: road tunnel & 5.9 & 0.6 & 0.2 & 0.5 \\
\hline
\end{tabular}

The future street layout slightly increases average risk in the case of the route that maximizes environmental quality, as it provides several additional opportunities for crossing along Seven Sisters Road because the surrounding links will have high PERS scores. In terms of the eight options for Seven Sisters Road, where the route choice objective is to minimize time or maximize environmental quality, the risk generally decreases with the number of traffic lanes, but under the 'minimize traffic' objective, risk scores increase when the number of traffic lanes in each direction is reduced from six to four, and is also higher under the two-lane and shared space design options than under the 'no intervention' scenario. This is explained by the fact that the improvements in the road will lead to a lower willingness to make a detour to use crossing facilities and thus to a higher propensity to cross the road informally.

\section{Results: Quality of the pedestrian environment}

The indicator of the quality of the pedestrian environment is the average of the PERS score on all chosen links and crossings, weighted by time spent traversing each of them. The results are shown in Table 6.

The future street layout scores much higher in terms of pedestrian environment than the past street layout, as it is designed to do. When we look at effects of the eight design options for Seven Sisters Road, the scores are the highest where the road is placed in a tunnel $(\mathrm{H})$, followed by the shared space $(\mathrm{G})$ and the options that widen sidewalks (D and F). In the fastest and 'minimum traffic' routes, all interventions are better than the no-intervention scenario, but that is not the case in the route choice alternative that maximizes environmental quality. 
TABLE 6 Average PERS scores for each scenario (\%)

\begin{tabular}{lcccc}
\hline Scenario & \multicolumn{5}{c}{ Routes } \\
\hline No changes to Seven Sisters Road & Shortest & Fastest & Min traffic & Max quality \\
\hline Past street layout & & & & \\
Past street layout (new buildings) & 45 & 45 & 46 & 53 \\
Future street layout & 46 & 46 & 47 & 53 \\
\hline
\end{tabular}

Changes to Seven Sisters Road (new street

layout)

\begin{tabular}{lllll}
\hline A: signalised crossings & 59 & 64 & 64 & 75 \\
B: underpasses & 59 & 63 & 62 & 74 \\
C: reduce speed limit & 59 & 64 & 64 & 74 \\
\hline D: wider sidewalk & 59 & 67 & 66 & 75 \\
E: wider median strip & 59 & 63 & 63 & 74 \\
\hline F: much wider sidewalk & 59 & 68 & 67 & 75 \\
\hline G: shared space & 59 & 67 & 66 & 75 \\
\hline H: road tunnel & 59 & 71 & 70 & 79 \\
\hline
\end{tabular}

\section{DISCUSSION AND CONCLUSIONS}

This paper has estimated the effectiveness of interventions to reduce the obstacles faced by pedestrians, considering their impacts on trip distance, delay, risk, and pedestrian environment. The results show that the changes in street layout will generally benefit local residents, regardless of the assumptions about the pedestrian route choice objective, as this results in reduced crossing delays and greatly increased quality of the pedestrian environment, although it may increase trip distance and collision risk, depending on the route objectives. Interventions in Seven Sisters Road bring additional benefits, especially in the case of options with fewer vehicle lanes, although these options do not achieve the same minimum value for risk that is achieved in the 'no intervention' scenario.

The method used in this paper provides a replicable means of assessing street performance from a pedestrian user perspective and is a useful tool to experiment with different options at the planning stage of a development scheme, when there is scope to modify proposals to maximize benefits to pedestrians. It is clear from this paper that the scale of these benefits is sensitive to the street layout and to the design of major roads.

This analysis could be refined by examining the sensitivity to some of the inputs, for example, expanding the set of destinations, assigning different values for walking speeds and for the willingness to walk to avoid risk for different population groups, assuming maximum walking distances or times, and differentiating between times of day, days of week, and meteorological conditions.

On the other hand, the methods used could also be simplified in order to be more readily applicable in practice. The time and cost required to empirically measure delay and to assess the pedestrian environment can be reduced by classifying links and crossings into different types, and then collect data for only a small sample of each type. The analysis could also exclude interventions that have similar costs but always achieve less benefits than others in terms of all four effects studied (for example, it was found that widening the road's median strip has less benefits than widening sidewalks); or it could be restricted to the study of the effects for which this paper found trade-offs (for example, between delay and risk).

The analysis could also focus on one or two effects only and estimate the trade-offs with other effects using theoretical relationships. For example, in the proposed method there is by 
definition a trade-off between the improvement of the pedestrian environment and trip duration, as it is assumed that the higher the PERS score, the less pedestrians will perceive walking time as a cost. Risk is also directly related to delay, as crossing time is a component of the formula that estimates risk. The extent to which environmental quality and risk will change following an intervention can therefore be deduced from the change in crossing delay, if we assume certain values for the other inputs in their formulas.

In most cases, the interventions on the street network will be less extensive than the ones studied in this paper, which is based in an area undergoing a radical transformation. As such, the values obtained here could be used as a benchmark for the maximum possible benefits that interventions can achieve in neighborhoods with similar dimensions and barriers to walking as in Woodberry Down. The assessment could then focus on the estimation of the extent to which the benefits for pedestrians fall below that maximum due to the restrictions in the number of links and crossings than can be altered.

\section{ACKNOWLEDGMENTS}

This paper is an output of the Street Mobility and Network Accessibility project, which is supported by the UK's Engineering and Physical Sciences, Economic and Social, and Arts and Humanities Research Councils. The authors would like to thank the other members of the project team, including: Jenny Mindell, Laura Vaughan, Muki Haklay, Shaun Scholes, Ashley Dhanani, Jemima Stockton, Nora Groce, and Shepley Orr. Comments from five anonymous reviewers are also gratefully acknowledged.

\section{REFERENCES}

1. Pucher, J., R. Buehler, D. R. Bassett, and A. L. Dannenberg. Walking and Cycling To Health: A Comparative Analysis of City, State, and International Data. American Journal of Public Health, Vol. 100, No. 10, 2010, pp. 1986-1992.

2. Ettema, D., and I. Smajic. Walking, Places and Wellbeing. The Geographical Journal, Vol. 181, No. 2, 2015, pp. 102-109.

3. Martin, A., Y. Goryakin, and M. Suhrcke. Does Active Commuting Improve Psychological Wellbeing? Longitudinal Evidence from Eighteen Waves of the British Household Panel Survey. Preventive Medicine, Vol.69, 2014, pp. 296-303.

4. Transportation Research Board. Does the Built Environment Influence Physical Activity: Examining the Evidence. Transportation Research Board and Institute of Medicine of the National Academies., Washington, D.C., 2005.

5. Forsyth, A., J. M. Oakes, B. Lee, and K. H. Schmitz. The Built Environment, Walking, and Physical Activity: Is The Environment More Important To Some People Than Others? Transportation Research D, Vol. 14, No. 1, 2009, pp.42-49.

6. Marshall, W. E., and N. W. Garrick. Effect of Street Network Design on Walking and Biking. In Transportation Research Record: Journal of the Transportation Research Board, No. 2198, Transportation Research Board of the National Academies, Washington, D.C., 2010, pp. 103-115.

7. Saelens, B. E., J. F. Sallis, and L. D. Frank. Environmental Correlates of Walking and Cycling: Findings from the Transportation, Urban Design, and Planning Literatures. Annals of Behavioral Medicine, Vol. 25, No. 2, 2003, pp. 80-91.

8. Hess, P.M, A. V. Moudon, M. C. Snyder, and K. Stanilov. Site Design and Pedestrian Travel. In Transportation Research Record: Journal of the Transportation Research Board, No. 1674, Transportation Research Board of the National Academies, Washington, D.C., 1999, pp. 9-19.

9. Appleyard, D., and M. Lintell. The Environmental Quality of City Streets: The Residents' Viewpoint. Journal of the American Institute of Planners, Vol. 38, No. 2, 1972, pp. 84-101. 
10. Sauter, D., and M. Huettenmoser. Livable Streets and Social Inclusion. Urban Design International, Vol. 13, 2008, pp. 67-79.

11. Sugiyama, T., M. Neuhaus, R. Cole, B. Giles-Corti, and N. Owen. Destination and Route Attributes Associated with Adults' Walking: A Review. Medicine and Science in Sports and Exercise, Vol. 44, No.7, 2012, pp.1275-1286.

12. Park, S., E. Deakin, and J. S. Lee. Perception-Based Walkability Index to Test Impact of Microlevel Walkability on Sustainable Mode Choice Decisions. In Transportation Research Record: Journal of the Transportation Research Board, No. 2464, Transportation Research Board of the National Academies, Washington, D.C., 2014, pp. 126-134.

13. Foster, S., B. Giles-Corti, and M. Knuiman. Does Fear of Crime Discourage Walkers? A Social-Ecological Exploration of Fear as a Deterrent to Walking. Environment and Behavior, Vol. 46, No. 6, 2014, pp. 698-717.

14. Mackett, R L., K. Achutan, and H. Titheridge. AMELIA: A Tool to Make Transport Policies More Socially Inclusive. Transport Policy, Vol. 15, No. 6, 2008, pp. 372-378.

15. Chin, G. K. W., K. P. Van Niel, B. Giles-Corti, and M. Knuiman. Accessibility and Connectivity in Physical Activity Studies: The Impact of Missing Pedestrian Data. Preventive Medicine, Vol. 46, No. 1, 2008, pp. 41-45.

16. Tal, G., and S. Handy. Measuring Non-Motorized Accessibility and Connectivity in a Robust Pedestrian Network. In Transportation Research Record: Journal of the Transportation Research Board, No. 2299, Transportation Research Board of the National Academies, Washington, D.C., 2012, pp. 48-56.

17. Guo, Z. Does The Pedestrian Environment Affect The Utility of Walking? A Case of Path Choice in Downtown Boston. Transportation Research D, Vol. 14, No. 5, 2009, pp. 343 352.

18. Olszewski, P., and S. S. Wibowo. Using Equivalent Walking Distance to Assess Pedestrian Accessibility to Transit Stations in Singapore. In Transportation Research Record: Journal of the Transportation Research Board, No. 1927, Transportation Research Board of the National Academies, Washington, D.C., 2005, pp. 38-45.

19. Jones, P., S. H. Wixey, H. Titheridge, and G. Christodoulou. Measuring Accessibility as Experienced by Different Socially Disadvantaged Groups. Working Paper 6: Developing Accessibility Planning Tools. University of Westminster, London, 2005. http://home.wmin.ac.uk/transport/download/SAMP_WP6_DevelopAccessibilityTools.pdf Accessed Mar.1, 2016.

20. Rodríguez, D. A., E. M. Brisson, and N. Estupiñán. The Relationship between SegmentLevel Built Environment Attributes and Pedestrian Activity around Bogota's BRT Stations. Transportation Research D, Vol. 14, No. 7, 2009, pp.470-478.

21. Byon, Y-J., B. Abdulhai, and A. Shalaby. Incorporating Scenic View, Slope, and Crime Rate into Route Choices - Emphasis on Three-Dimensional Geographic Information Systems with Digital Elevation Models and Crime Rate Geospatial Data. In Transportation Research Record: Journal of the Transportation Research Board, No. 2183, Transportation Research Board of the National Academies, Washington, D.C., 2010, pp. 94-102.

22. Muraleetharan, T., and T. Hagiwara. Overall Level of Service of Urban Walking Environment and Its Influence on Pedestrian Route Choice Behavior - Analysis of Pedestrian Travel in Sapporo, Japan. In Transportation Research Record: Journal of the Transportation Research Board, No. 2002, Transportation Research Board of the National Academies, Washington, D.C., 2007, pp. 7-17.

23. Guo, Z., and B. P. Y. Loo. Pedestrian Environment and Route Choice: Evidence From New York City and Hong Kong. Journal of Transport Geography, Vol. 28, 124-136.

24. Dowling, R., A. Flannery, B. Landis, T. Petritsch, N. Rouphail, and P. Ryus. Multimodal Level of Service for Urban Streets. In Transportation Research Record: Journal of the 
Transportation Research Board, No. 2071, Transportation Research Board of the National Academies, Washington, D.C., 2008, pp. 1-7.

25. Matrix Partnership, Shepheard Epstein Hunter, S. Wilson, and Bernard Williams Associates. Woodberry Down Planning Application - Masterplan. Document prepared for Hackney Homes Ltd. on behalf of London Borough of Hackney, 2007. http://www.hackney.gov.uk/planning-majoraps.htm\#woodberry. Accessed Mar.1, 2016.

26. Fletcher Priest Architects and Townshend. Woodberry Down Masterplan Review. Document prepared for Berkeley Homes, 2013. https://fb.docs.com/XOOH. Accessed Aug.1, 2015.

27. Clark, S., and A. Davies. Identifying and Prioritising Walking Investment through the PERS Audit Tool. Presented at Walk 21 Conference, New York, 2009.

28. Transport Research Laboratory. Street Audit - Pedestrian Mode. On-Street Assessment Handbook, Version SA1.1.Transport Research Laboratory., Crowthorne, 2010.

29. Routledge, D., R. Repetto-Wright, and I. Howarth. The Exposure of Young Children to Accident Risk as Pedestrians. Ergonomics, Vol. 17, No. 4, 1974, pp. 457-480. 